This article is licensed under the Creative Commons Attribution-NonCommercial 4.0 International License (CC BY-NC) (http://www.karger.com/Services/OpenAccessLicense). Usage and distribution for commercial purposes requires written permission.

\title{
Metastatic Intimal Sarcoma of the Pulmonary Artery Sensitive to Carboplatin-Vinorelbine Chemotherapy: Case Report and Literature Review
}

\author{
Marie Cantaloube ${ }^{a} \quad$ Laurence Moureau-Zabotto $^{b} \quad$ Lena Mescam $^{c}$ \\ Audrey Monneur ${ }^{a}$ Valeria Deluca $^{d}$ Jerome Guiramand ${ }^{\mathrm{e}}$ \\ Delphine Perrot ${ }^{a} \quad$ François Bertucci ${ }^{a, f}$
}

${ }^{a}$ Department of Medical Oncology, Centre de Recherche en Cancérologie de Marseille (CRCM), Institut Paoli-Calmettes, Marseille, France; ${ }^{b}$ Department of Radiotherapy, Institut Paoli-Calmettes, Marseille, France; ${ }^{C}$ Department of Pathology, Institut Paoli-Calmettes, Marseille, France; ${ }^{d}$ Department of Radiology, Institut Paoli-Calmettes, Marseille, France; ${ }^{e}$ Department of Surgery, Institut Paoli-Calmettes, Marseille, France; ${ }^{f}$ Faculty of Medicine, Aix-Marseille University, Marseille, France

\section{Keywords}

Carboplatin · Chemotherapy · Intimal sarcoma of the pulmonary artery · Vinorelbine

\begin{abstract}
Pulmonary artery intimal sarcoma (PAIS) is a very rare tumour with a very poor prognosis. In advanced stages, chemotherapy and radiotherapy are poorly efficient, and no standard chemotherapy guideline is currently available. Here, we report on a 37-year-old woman with PAIS initially treated with surgical resection who developed metastatic relapse refractory to anthracycline-based chemotherapy, then trabectedin, then pazopanib. The patient was then given carboplatin-vinorelbine chemotherapy. The treatment was well tolerated, and, rapidly, a CT scan showed an objective response that lasted 8 months despite the 4 th therapeutic
\end{abstract}




\section{Case Reports in Oncology}

line. We review the literature and show that our case is the second one that provides evidence of the efficacy of platinum-vinorelbine regimens in this aggressive tumour.

(C) 2018 The Author(s)

Published by S. Karger AG, Basel

\section{Introduction}

Pulmonary artery intimal sarcoma (PAIS) is a very rare tumour. The first description was reported in 1923 by Mandelstamm after an autopsy [1]. The incidence of pulmonary artery sarcomas is estimated between 0.001 and $0.003 \%$, but is likely underestimated because of frequent misdiagnosis. There is a slight female predominance $(1.3 / 1)$, and it mainly occurs in middle-aged adults. Common symptoms at the time of diagnosis look like those of pulmonary embolism, including dyspnoea, chest pain, and cough, but they occur more progressively.

Given the scarcity of the disease, only case reports and small retrospective series are reported in the literature. The prognosis is very poor, with median overall survival below 18 months [2]. In early stages, the treatment of choice is complete surgical resection, and the role of adjuvant chemotherapy and radiotherapy remains controversial. In advanced stages, some studies have reported that chemotherapy and radiotherapy may be effective $[3,4]$, but no standard therapeutic guideline is currently available.

Here, we report on a 37-year-old woman with PAIS initially treated with surgical resection who developed metastatic relapse successfully treated in the 4 th line with carboplatinvinorelbine chemotherapy.

\section{Case Presentation}

In September 2014, a 34-year-old Caucasian woman presenting with asthenia, fever, and systolic murmur was diagnosed with an obstructive tumour in the pulmonary artery evoking a myxoma. There was no specific familial and medical personal history. The radiological assessments had eliminated an infectious endocarditis and pulmonary embolism. She underwent surgical resection. A pathological analysis of the operative specimen revealed a tumour with atypical pleomorphic cells, with a high mitotic count $(>20 / 10$ high-power fields), and necrosis. Immunohistochemistry showed that the tumour cells were positive for vimentin and CD34 (heterogeneous staining), but negative for CD45, S-100 protein, HMB45, CD31, ERG, and caldesmon. FISH (fluorescence in situ hybridization) analysis showed MDM2 amplification in the tumour cells. The diagnosis of high-grade PAIS was retained after expert pathologic review within the French Sarcoma Network (Réseau de Référence en Pathologie des Sarcomes, RRePS). After surgery, the patient received four cycles of adjuvant chemotherapy combining Adriamycin and ifosfamide between November 2014 and February 2015.

In November 2015, she experienced a first pulmonary metastatic relapse with multiple bilateral nodules and micronodules, for which she received a 1st line of chemotherapy combining gemcitabine and dacarbazine. This regimen was stopped in February 2016 after 3 cycles because of pulmonary progression. She then underwent a 2 nd metastatic treatment 


\section{Case Reports in Oncology}

Case Rep Oncol 2018;11:21-28

DOI: $10.1159 / 000485740$

(C) 2018 The Author(s). Published by S. Karger AG, Basel www.karger.com/cro

Cantaloube et al.: Metastatic Intimal Sarcoma of the Pulmonary Artery Sensitive to

Carboplatin-Vinorelbine Chemotherapy: Case Report and Literature Review

line with trabectedin from March 2016 to May 2016, which again was stopped after 3 cycles because of pulmonary progression. In May 2016, she started a 3rd metastatic treatment line with pazopanib (800 mg/day), stopped for pulmonary progression in December 2016. External beam radiation therapy (total dose of 30 Gy in 10 fractions and 2 weeks) was then delivered as analgesic radiation of a right subpleural pulmonary metastasis.

In December 2016, she was referred to our institution. Her performance status was zero and there was no medical symptom. She was included in our high-throughput molecular screening trial (PERMED-01 trial, NCT02342158) and a pulmonary biopsy was performed, confirming the diagnosis of metastasis from the PAIS (Fig. 1) with MDM2 amplification, associated with $C D K 4$ amplification. In February 2017, we started a 4th-line chemotherapy based on the combination of carboplatin and vinorelbine (area under curve [AUC] 5 on day 1 and vinorelbine $25 \mathrm{mg} / \mathrm{m}^{2} /$ day on days 1 and 8, every 21 days). The treatment was very well tolerated without any grade 3-4 toxicity. After 3 cycles (April 2017), a CT scan revealed objective regression of the subdiaphragmatic lesions (Fig. 2a-h). After six cycles (June 2017), the lesions further decreased at the mediastinal and pleuropulmonary levels, with stability of the other pulmonary lesions and no new lesion (Fig. 2i-l). Because of this increasing efficiency and perfect tolerance, we decided to pursue the treatment with 3 additional cycles. After the 9th cycle, in October 2017, the PS was zero without any clinical symptom, but the CT scan showed disease progression with an increase in size of two lesions (Fig. 2m-p) and stability of the other lesions. The chemotherapy was thus stopped and the patient is going to start stereotaxic radiotherapy on both progressive lesions.

\section{Discussion}

Intimal sarcoma of the pulmonary artery is a rare tumour, but very aggressive. Intimal sarcoma arises in large vessels, more frequently in the pulmonary artery than in the aorta. Even after complete surgery, the prognosis of PAIS is poor because of frequent relapses, more often local than distant. In advanced stages, chemotherapy is poorly efficient. We here report the case of a young woman who experienced an objective response to 4th-line chemotherapy based on carboplatin plus vinorelbine.

The clinical symptoms of PAIS are not specific; most often they include dyspnoea, haemoptysis, chest pain, and cough. The initially suspected clinical diagnosis is often pulmonary embolism [5], making the diagnosis of PAIS often too late, at which time the disease is locally advanced. The pathological diagnosis is generally made on a surgical biopsy or on the surgical resection specimen, like with our patient.

The prognosis is extremely poor, notably in the absence of complete surgical resection or when the disease relapses. Systemic therapy has never been specifically assessed for intimal sarcomas, and the best chemotherapy regimen, if any, remains to be defined. Anthracyclines, especially doxorubicin, are a standard drug in the treatment of soft tissue sarcomas [6]. In patients with PAIS, they have been used either alone or more frequently in combination. Our literature review identified 11 patients who were informative for their tumour response after such a regimen $[2,3,5,7-10]$. There were 3 objective responses ( 1 complete and 2 partial) and 8 had progressive disease, mirroring the $\sim 20 \%$ objective response rate observed with anthracycline-based regimens in soft tissue sarcomas. In our case report, the 
patient relapsed less than 9 months after the adjuvant doxorubicin-ifosfamide regimen, suggesting poor sensitivity to this treatment.

Other drugs classically used in soft tissue sarcomas include ifosfamide, dacarbazine, gemcitabine with and without docetaxel, trabectedin, and pazopanib [6]. In the metastatic setting, our patient received 3 ineffective cycles of gemcitabine-dacarbazine, then 3 ineffective cycles of trabectedin, then pazopanib with disease stabilization after 3 months but progression after 7 months. By contrast, and despite the fact that this was the 4th therapeutic line, she showed a strong response to carboplatin-vinorelbine after 3, then 6 cycles. Even if the response lasted only 8 months, it clearly suggested an activity of such a regimen on PAIS. To our knowledge, there is one other case of response with a similar regimen in the literature [11] (Table 1). This case showed stabilization of pulmonary metastases after 2 cycles combining doxorubicin, cisplatin, and ifosfamide that were poorly tolerated. The patient thus received 4 cycles combining cisplatin and vinorelbine as the 2 nd therapeutic line, which was better tolerated and led to a remarkable partial response that further improved under maintenance oral cyclophosphamide. However, in this case, although there was insufficient shrinkage to qualify for partial response after the 1st-line doxorubicin-cisplatin-ifosfamide regimen, the tumour had significantly decreased in size after 2 cycles, suggesting a sensitivity to these drugs, and not only to the cisplatin-vinorelbine combination. In our patient, the tumour responded to carboplatin-vinorelbine, whereas it was clearly refractory to the previous therapeutic regimens. In adult patients, vinorelbine is not a drug classically efficient in soft tissue sarcomas, except in other vascular sarcomas, i.e., angiosarcomas [12,13] and AIDS-related Kaposi sarcoma [14], whereas its activity has been more frequently reported in childhood sarcomas [15].

In conclusion, we report the first case of advanced PAIS that clearly responded to the combination of vinorelbine with carboplatin, and the second one responding to a combination of vinorelbine with a platinum salt. The treatment was well tolerated and efficient despite the fact that it was used in the 4th line, and may thus represent a good choice for chemotherapy in such patients.

\section{Acknowledgements}

Our work is supported by the Institut Paoli-Calmettes.

\section{Statement of Ethics}

We thank our patient, who kindly gave her consent for this publication.

\section{Disclosure Statement}

The authors declare no conflict of interest. 


\section{Case Reports in Oncology}

\section{References}

1 Mandelstamm M: Über primäre Neubildungen des Herzens. Virchows Arch Pathol Anat 1923;245:4354.

2 Kriz JP, Munfakh NA, King GS, Carden JO: Pulmonary artery intimal sarcoma: a case report. Case Rep Oncol 2016;9:267-272.

- Hirose T, Ishikawa N, Hamada K, Inagaki T, Kusumoto S, Shirai T, Okuda K, Ohnishi T, Kadokura M, Adachi M: A case of intimal sarcoma of the pulmonary artery treated with chemoradiotherapy. Intern Med 2009;48:245-249.

44 Secondino S, Grazioli V, Valentino F, Pin M, Pagani A, Sciortino A, Klersy C, Callegari MG, Morbini P, Dore R, Paulli M, Pedrazzoli P, D'Armini AM: Multimodal approach of pulmonary artery intimal sarcoma: a single-institution experience. Sarcoma 2017;2017:7941432.

-5 Yamamoto K, Nozue T, Tsuchida M, Iwaki T, Nagamine H, Yasuda T, Kawase H, Matsushita K, Michishita I: Pulmonary embolism caused by intimal sarcoma of the pulmonary artery. Intern Med 2012;51:30313034.

6 Linch M, Miah AB, Thway K, Judson IR, Benson C: Systemic treatment of soft-tissue sarcoma-gold standard and novel therapies. Nat Rev Clin Oncol 2014;11:187-202.

-7 Funatsu Y, Hirayama M, Shiraishi J, Asakura T, Wakaki M, Yamada E, Fujimoto K, Satomi R, Inaki S, Murata Y, Oyamada Y: Intimal sarcoma of the pulmonary artery treated with pazopanib. Intern Med 2016;55:2197-2202.

8 Penel N, Taieb S, Ceugnart L, Dansin E, Hoguet D, Vanseymortier L, Lartigau E: Report of eight recent cases of locally advanced primary pulmonary artery sarcomas: failure of doxorubicin-based chemotherapy. J Thorac Oncol 2008;3:907-911.

-9 Chen X, Ren S, Li A, Zhou C: A case report of chemo-sensitive intimal pulmonary artery sarcoma. Cell Biochem Biophys 2014;68:153-157.

10 Wong HH, Gounaris I, McCormack A, Berman M, Davidson D, Horan G, Pepke-Zaba J, Jenkins D, Earl HM, Hatcher HM: Presentation and management of pulmonary artery sarcoma. Clin Sarcoma Res 2015;5:3.

11 Xu Y, Wang K, Geng Y, Shao Y, Yin Y: A case of intimal sarcoma of the pulmonary artery successfully treated with chemotherapy. Int J Clin Oncol 2012;17:522-527.

12 Read WL, Williams F: Metastatic angiosarcoma with Kasabach-Merritt syndrome responsive to gemcitabine and vinorelbine after failure of liposomal doxorubicin and paclitaxel: a case report. Case Rep Oncol 2016;9:177-181.

13 Anderson SE, Keohan ML, D’Adamo DR, Maki RG: A retrospective analysis of vinorelbine chemotherapy for patients with previously treated soft-tissue sarcomas. Sarcoma 2006;2006:15947.

-14 Nasti G, Errante D, Talamini R, Rizzardini G, Fasan M, Landonio G, Zeroli C, Chichino G, Nigra E, Vaccher E, Tirelli U: Vinorelbine is an effective and safe drug for AIDS-related Kaposi's sarcoma: results of a phase II study. J Clin Oncol 2000;18:1550-1557.

-15 Casanova M, Ferrari A, Bisogno G, Merks JH, De Salvo GL, Meazza C, Tettoni K, Provenzi M, Mazzarino I, Carli M: Vinorelbine and low-dose cyclophosphamide in the treatment of pediatric sarcomas: pilot study for the upcoming European Rhabdomyosarcoma Protocol. Cancer 2004;101:1664-1671.

L.M.-Z., L.M., J.G., D.P., and F.B. are members of the French Sarcoma Group. 


\section{Case Reports in Oncology}

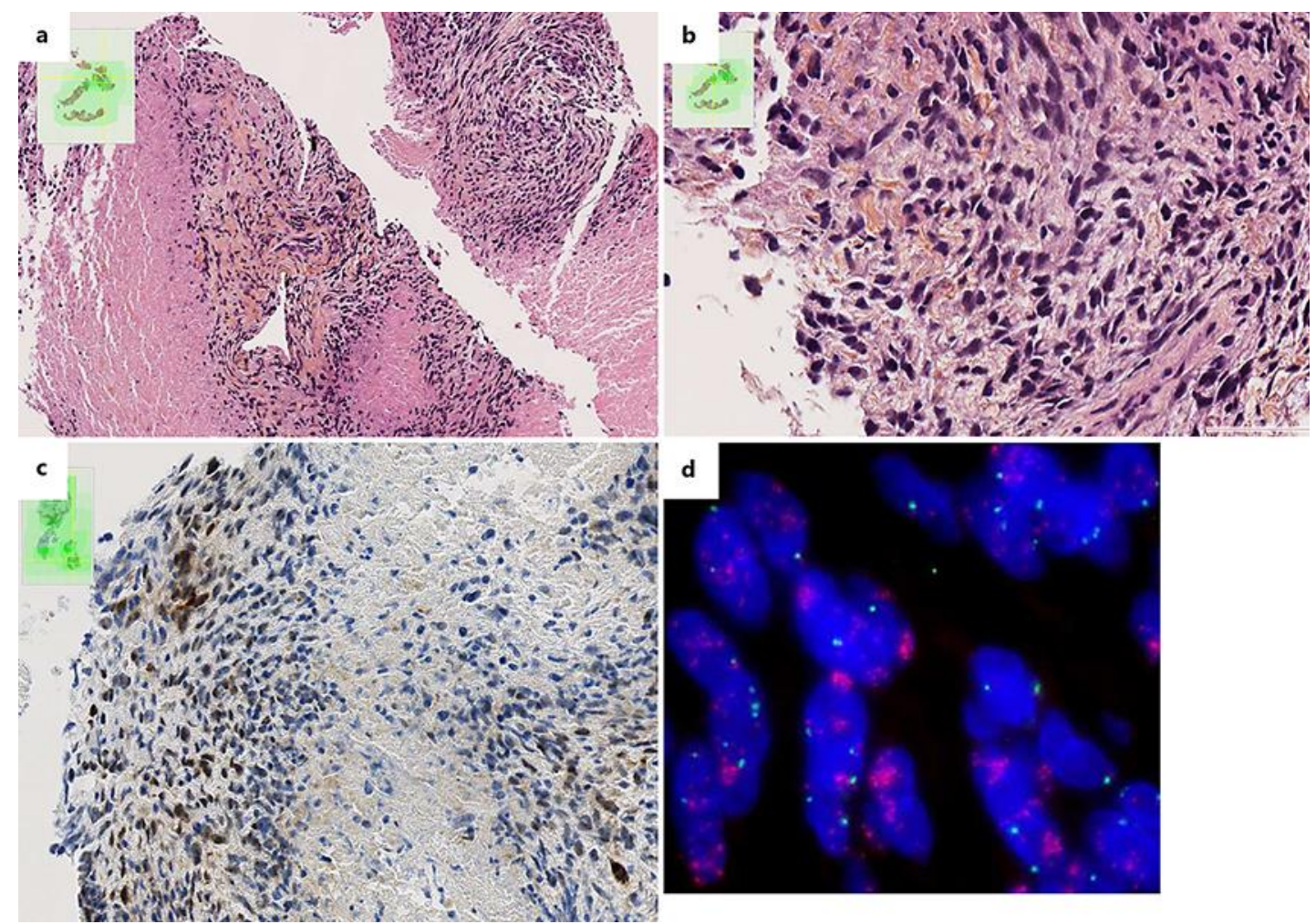

Fig. 1. Pathological aspects of the pulmonary metastasis from the pulmonary artery intimal sarcoma. a Hematoxylin-eosin-saffron (HES) staining of the pulmonary biopsy showing a poorly differentiated necrotic lesion. $\times 10$. $\mathbf{b}$ The spindle tumour cells are severely atypical with numerous mitoses. HES. $\times 40$. $\mathbf{c}$ Immunohistochemistry staining showing expression of MDM2 by tumour cells. $\mathbf{d}$ FISH analysis showing numerous red signals in tumour cells revealing an amplification of the $12 q 15$ region, which contains the MDM2 gene. 


\section{Case Reports in Oncology}

January 2017
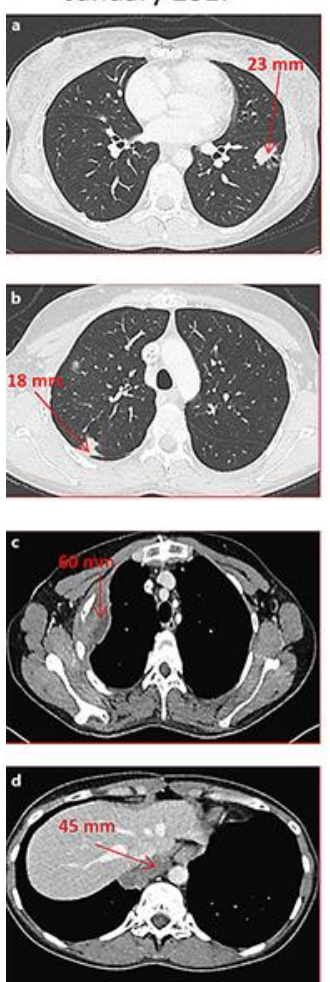

April 2017
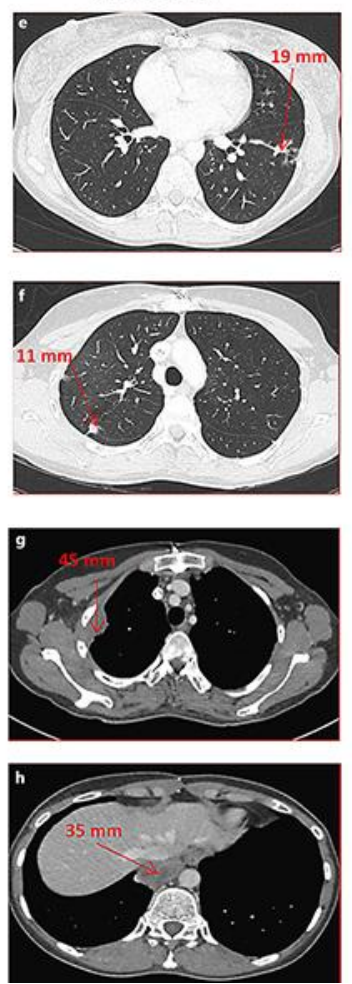

June 2017
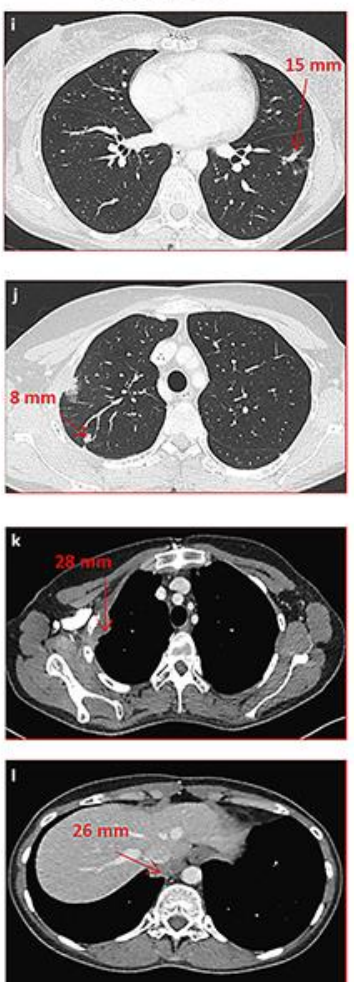

October 2017
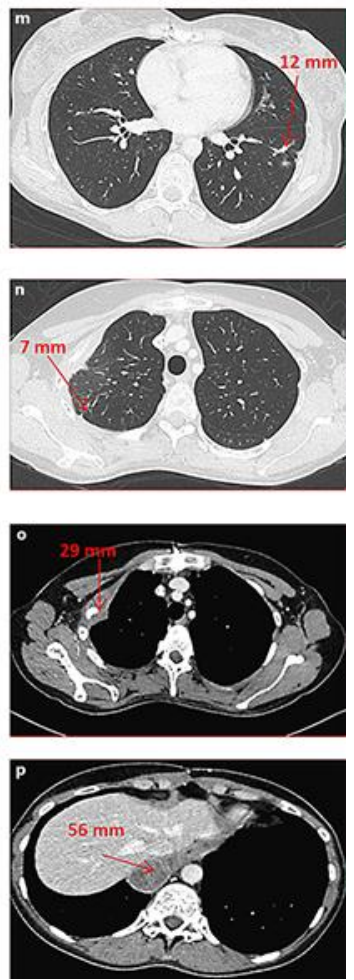

Fig. 2. Radiological response to carboplatin-vinorelbine chemotherapy. Chest CT scans during 4 successive periods of treatment with carboplatin-vinorelbine. a-d January 2017, before the 1st cycle. Four lesions are shown (red arrows): 2 intraparenchymal lesions (a, b), 1 lesion in contact with the second rib (c), and 1 lesion of the right posterior inframediastinal space (d). e-h April 2017, after 3 cycles. Regression of all 4 lesions. i-I June 2017, after 6 cycles. Continued regression of all 4 lesions. $\mathbf{m}$-p October 2017, after 9 cycles. Stability of the intraparenchymal lesions $(\mathbf{m}, \mathbf{n})$, but progression of the inframediastinal lesion $(\mathbf{p})$ and the lesion in contact with the second rib (o). 


\section{Case Reports in Oncology}

Case Rep Oncol 2018;11:21-28
\begin{tabular}{l|l} 
DOI: $10.1159 / 000485740$ & $\begin{array}{l}\text { C } 2018 \text { The Author(s). Published by S. Karger AG, Basel } \\
\text { www.karger.com/cro }\end{array}$ \\
\hline
\end{tabular}

Cantaloube et al.: Metastatic Intimal Sarcoma of the Pulmonary Artery Sensitive to

Carboplatin-Vinorelbine Chemotherapy: Case Report and Literature Review

Table 1. Radiological responses of the metastatic pulmonary artery intimal sarcoma reported after a combination of vinorelbine and platinum salt

\begin{tabular}{|c|c|c|c|c|c|c|c|c|}
\hline Ref. & $\begin{array}{l}\text { Gender/ } \\
\text { age, years }\end{array}$ & $\begin{array}{l}\text { Lesions } \\
\text { evaluated }\end{array}$ & $\begin{array}{l}\text { Number of lines and } \\
\text { regimens before } \\
\text { platinum-vinorelbine }\end{array}$ & $\begin{array}{l}\text { Platinum-vinorelbine: } \\
\text { doses/cycle }\end{array}$ & Cycles & $\begin{array}{l}\text { Best } \\
\text { response }\end{array}$ & Duration of response & $\begin{array}{l}\text { Status at last } \\
\text { follow-up }\end{array}$ \\
\hline 11 & $\mathrm{~F} / 55$ & $\begin{array}{l}1 \text { mass in the } \\
\text { right } \\
\text { upper lobe }\end{array}$ & $\begin{array}{l}1 \text { line: } \\
\text { doxorubicin }+ \\
\text { cisplatin }+ \\
\text { ifosfamide } \\
\text { (2 cycles) }\end{array}$ & $\begin{array}{l}\text { Cisplatin } \\
\left(30 \mathrm{mg} / \mathrm{m}^{2} / \text { day }\right. \\
\text { on D } 1-3) \\
+ \\
\text { vinorelbine } \\
\left(25 \mathrm{mg} / \mathrm{m}^{2} / \text { day }\right. \\
\text { on D1 })\end{array}$ & $\begin{array}{l}4 \text { cycles } \\
\text { every } \\
21 \text { days }\end{array}$ & $\begin{array}{l}\text { Partial } \\
\text { response }\end{array}$ & $\begin{array}{l}\text { Difficult to assess } \\
\text { because of continuous } \\
\text { regression of the tumor } \\
\text { under maintenance oral } \\
\text { cyclophosphamide }\end{array}$ & $\begin{array}{l}\text { Alive with stable } \\
\text { disease }\end{array}$ \\
\hline $\begin{array}{l}\text { Our } \\
\text { case }\end{array}$ & $\mathrm{F} / 34$ & $\begin{array}{l}\text { Lung: } \\
4 \text { lesions }\end{array}$ & $\begin{array}{l}3 \text { lines: } \\
\text { - gemcitabine }+ \\
\text { dacarbazine }(6 \text { cycles }) \\
\text { - trabectedin }(3 \text { cycles }) \\
\text { - pazopanib ( } 7 \text { months })\end{array}$ & $\begin{array}{l}\text { Carboplatin (AUC } 5 \\
\text { on D1) } \\
+ \\
\text { vinorelbine } \\
\left(25 \mathrm{mg} / \mathrm{m}^{2} / \text { day }\right. \\
\text { on D1 and D8) }\end{array}$ & $\begin{array}{l}9 \text { cycles } \\
\text { every } \\
21 \text { days }\end{array}$ & $\begin{array}{l}\text { Partial } \\
\text { response }\end{array}$ & 8 months & $\begin{array}{l}\text { Alive, with } \\
\text { progression of } 2 \\
\text { lesions }\end{array}$ \\
\hline
\end{tabular}

D, day; AUC, area under curve. 